\title{
Surface energy balance characteristics of a heterogeneous urban ballast facet
}

\author{
Stephan Weber*, Wilhelm Kuttler \\ Department of Applied Climatology and Landscape Ecology, Institute of Geography, University of Duisburg-Essen, \\ Campus Essen, 45141 Essen, Germany
}

\begin{abstract}
Surface energy balance measurements were conducted during a study period from June to September 2002 at a goods station in Osnabrück, Germany. The inner-urban facet with a surface area of $0.5 \mathrm{~km}^{2}$ was predominantly covered by ballast. Turbulent latent and sensible heat fluxes were estimated by a modified Bowen ratio method; the ground heat flux was calculated from temperature gradients and a laboratory derived thermal conductivity. The thermal behaviour of the ballast facet in comparison to other urban surfaces is somewhat 'two-sided'. Due to its thermal properties it behaves similarly to urban surfaces during the day, with high surface temperatures and large nearsurface temperature amplitudes. About one-third of the incoming energy is converted into the turbulent sensible heat flux and $20 \%$ is converted into the ground heat flux. The latent heat flux at the site is of minor importance (16\%). During the night, however, the thermal behaviour is more comparable to a 'rural-like' surface than to an urban facet. The ballast surface cools significantly and the sensible heat flux is directed towards the surface. Due to the heterogeneity of the study site the energy balance shows a closure gap of around $30 \%$. Reasons for the energy balance non-closure are discussed.
\end{abstract}

KEY WORDS: Surface energy balance $\cdot$ Ballast · Osnabrück · Thermal properties · Energy balance closure $\cdot$ Urban climate

\section{INTRODUCTION}

Studies on the energy balance characteristics at the earth's surface are important to better understand the evolution and properties of different micro- and mesoclimates and also to enhance their representation in numerical weather and climate models. Therefore detailed knowledge of the energy balance properties of various surface types is of interest. Measurements of turbulent fluxes over homogeneous surfaces which are 'ideal' in terms of the flux methodology have been performed for some decades (e.g. Businger et al. 1971, Panofsky et al. 1977, Nieuwstadt 1984, Wyngaard 1990, Dabberdt et al. 1993); however, recently, more sites are established in more complex and heterogeneous terrain such as urban areas, mixed land-use or coastal zones. With an increasing complexity in the footprint of the surface flux, demands on measurements, methodology and interpretation of energy bal- ance estimates can become complicated and challenging (Panin et al. 1998, Schmid \& Lloyd 1999, Massman \& Lee 2002). However, increased understanding of these 'real-world' surfaces is important for a wide range of research fields.

In urban areas complications arise due to the 3-dimensional, heterogeneous structure of the surface. In the context of urban flux measurements the city is normally treated in a box or volume approach so that the fluxes measured at the upper part of the box could be interpreted as representative local-scale flux estimates (Oke 1987, 1997). The actual measurement sites have to be installed within the urban constant flux layer, i.e. at a height above the so-called urban roughness sublayer, where individual surface roughness elements (i.e. buildings) have a direct influence on the turbulence structure (Rotach 1999, Marth 2000). The height of the urban roughness sublayer is site-specific, but is usually situated between 1.5 and 5 times the 
mean building height (Roth 2000). Studies on the urban energy balance on a city scale have been conducted in European cities such as Basel, Switzerland (Christen et al. 2003, Christen \& Vogt 2004), Marseille, France (Grimmond et al. 2002), and Barcelona, Spain (Jauregui et al. 2002). Furthermore, a variety of studies from other parts of the world and from different climatic regions have been published (see detailed reviews in Arnfield 2001a,b, 2003, McKendry 2003). However, a total urban flux within the footprint or source area of interest is mostly composed of different flux fractions triggered by the thermal and physical properties of specific urban facets such as roofs, walls, streets and different land-use types within the flux source area. To gain a better understanding of urban fluxes, urban microclimates and climatic phenomena such as the urban heat island and cold-air dynamics, more information on the energy budgets of specific urban facets is needed (Arnfield 2003).

Only a few studies concentrate on the energetic features of urban facets, e.g. asphalt (Anandakumar 1999), pavements of different porosity (Asaeda et al. 1996, Asaeda \& Vu 1997), urban canyon facets (Nunez \& Oke 1977) and urban parks (Barradas et al. 1999, Spronken-Smith et al. 2000). Some progress has been made in the field of numerically modelling the urban energy balance. The model domains mostly lack the methodological limitations that might appear when installing sensors in urban areas. However, the models also often concentrate on calculating the energy fluxes as local-scale estimates, hence considering the city as a whole (e.g. Grimmond \& Oke 2002, Roberts et al. 2003). Recently, Barlow et al. (2004) and Harman et al. (2004) attempted to quantify the contribution of different urban canyon facets (roof, walls and floor) to the total flux by a physical scale model and a numerical model.

The intention of this study is to characterise the surface energy balance of a plane inner-urban facet. Measurements were conducted at a goods station in Osnabrück, Germany. The results of this analysis in conjunction with additional measurement campaigns (Weber \& Kuttler 2004) are important in understanding the microclimatic effect of a ballast facet with regards to nocturnal cold-air dynamics and the general urban climatic situation of the city of Osnabrück. A detailed understanding of these phenomena plays an important role in urban climate related decision-making processes and for instance in the field of sustainable urban planning.

In Section 2, a brief summary of the main aspects of energy balance measurements is given, while the materials and methods used are described in Section 3. The results on surface heat fluxes are presented in Section 4 and concluded by a brief discussion in Section 5 .

\section{THEORY}

Nowadays, the measurement of turbulent sensible $\left(Q_{\mathrm{H}}\right)$ and latent $\left(Q_{\mathrm{E}}\right)$ heat fluxes is mostly done by fast response sensors $(>10 \mathrm{~Hz})$. Wind vectors are determined by sonic anemometers while humidity fluctuations are measured by absorption of water vapour in the infrared or Lyman alpha (ca. $122 \mathrm{~nm}$ ) range (e.g. Foken 2003). In case fast response humidity measurements are not available, Liu \& Foken (2001) proposed a method to gather $Q_{\mathrm{H}}$ and $Q_{\mathrm{E}}$ by a modified Bowen ratio method. The accuracy of this method to determine turbulent fluxes in comparison to eddy covariance measurements has been shown to be in the order of $<10 \%$ for $Q_{\mathrm{H}}$ and $<20 \%$ for $Q_{\mathrm{E}}$ (Liu \& Foken 2001). The approach is described in the original paper but is briefly summarised here.

The ratio of the sensible and latent fluxes is known as Bowen's ratio (Bo):

$$
\text { Bo }=\frac{Q_{\mathrm{H}}}{Q_{\mathrm{E}}}
$$

where both $Q_{\mathrm{H}}$ and $Q_{\mathrm{E}}$ are in $\mathrm{W} \mathrm{m}^{-2}$. Bo can be calculated from air temperature and humidity measurements at 2 levels above ground as (e.g. Arya 2001, Liu \& Foken 2001):

$$
\text { Bo }=\frac{C_{\mathrm{p}}}{L_{\mathrm{e}}} \frac{\Delta T}{\Delta q}
$$

where $c_{\mathrm{p}}$ is the specific heat capacity of air at constant pressure in $\mathrm{J} \mathrm{kg}^{-1} \mathrm{~K}^{-1}, L_{\mathrm{e}}$ is the latent heat of vaporisation of water in $\mathrm{J} \mathrm{kg}^{-1}, \Delta T$ is the vertical air temperature gradient in $\mathrm{K} \mathrm{m}^{-1}$ and $\Delta q$ is the vertical gradient of specific humidity in $\mathrm{kg} \mathrm{kg}^{-1} \mathrm{~m}^{-1}$.

In the first step of the modified Bo, $Q_{\mathrm{H}}$ is estimated by direct measurements of the buoyancy flux $\left(Q_{\mathrm{HB}}\right.$ $\mathrm{K} \mathrm{m} \mathrm{s}^{-1}$ ) with a sonic anemometer as:

$$
Q_{\mathrm{HB}}=\overline{W^{\prime} T_{\mathrm{s}}^{\prime}}
$$

where $w^{\prime}$ and $T_{\mathrm{S}}{ }^{\prime}$ are the turbulent fluctuations of vertical wind speed in $\mathrm{m} \mathrm{s}^{-1}$ and acoustic temperature (sonic temperature) in $\mathrm{K}$, respectively. The horizontal bar refers to averages over a certain time period (normally $30 \mathrm{~min}$ ) while the primed quantities refer to turbulent fluctuations during the averaging interval.

To correct for influences of crosswind and humidity fluctuations (Liu \& Foken 2001), Bo is needed. Finally, the conversion into sensible heat flux is calculated as:

$$
Q_{\mathrm{H}}=\rho \cdot c_{\mathrm{p}} \frac{\left(\overline{W^{\prime} T_{\mathrm{s}}^{\prime}}+2 \frac{\bar{T} \cdot \bar{u}}{\overline{C^{2}}} \cdot \overline{u^{\prime} W^{\prime}}\right)}{\left(1+\frac{0.51 \cdot \bar{T} \cdot c_{\mathrm{p}}}{L_{\mathrm{e}} \cdot \mathrm{Bo}}\right)}
$$


where $\rho$ is the density of air in $\mathrm{kg} \mathrm{m}^{-3}, T$ the air temperature in $\mathrm{K}, u$ the horizontal wind velocity in $\mathrm{m} \mathrm{s}^{-1}$, and $C$ the speed of sound in $\mathrm{m} \mathrm{s}^{-1}$. In the original papers (Liu \& Foken 2001, Liu et al. 2001) an improved equation is also given for the sonic anemometers that calculate the temperature from an average along all 3 sonic paths (not shown here).

In a final step, $Q_{\mathrm{E}}$ is estimated as:

$$
Q_{\mathrm{E}}=\frac{Q_{\mathrm{H}}}{\mathrm{Bo}}
$$

The ground heat flux $\left(Q_{\mathrm{G}}, \mathrm{W} \mathrm{m}^{-2}\right)$ can be calculated from the Fourier law of heat conduction as:

$$
Q_{\mathrm{G}}=\lambda \frac{\partial T}{\partial z}
$$

where $\lambda$ is the thermal conductivity in $\mathrm{W} \mathrm{m} \mathrm{m}^{-1} \mathrm{~K}^{-1}$, and $\partial T / \partial z$ is the gradient of soil temperature in $\mathrm{K} \mathrm{m}^{-1}$.

\section{MATERIALS AND METHODS}

3.1. Study site. From 12 June to 23 September 2002, energy balance measurements were conducted at a goods station (GS) in Osnabrück, Germany $\left(52^{\circ} 16^{\prime} \mathrm{N}\right.$, $\left.8^{\circ} 04^{\prime} \mathrm{E}\right)$. The GS is situated roughly within the centre of the urban area of Osnabrück and covers a surface area of approximately $0.5 \mathrm{~km}^{2}$ (Fig. 1). It is bordered by the urban centre to the west (building heights on average 12 to $16 \mathrm{~m}$ ), a commercial area to the south and a residential district to the north (building heights on average 8 to $12 \mathrm{~m}$ ). The eastern surroundings of the study area are characterised by large percentages of unsealed natural surfaces including meadow, agricultural crop land and pasture.

The surface of the GS is mainly comprised of ballast (a mixture of shattered rock types which predominately consists of greywacke, sandstone and diabase)

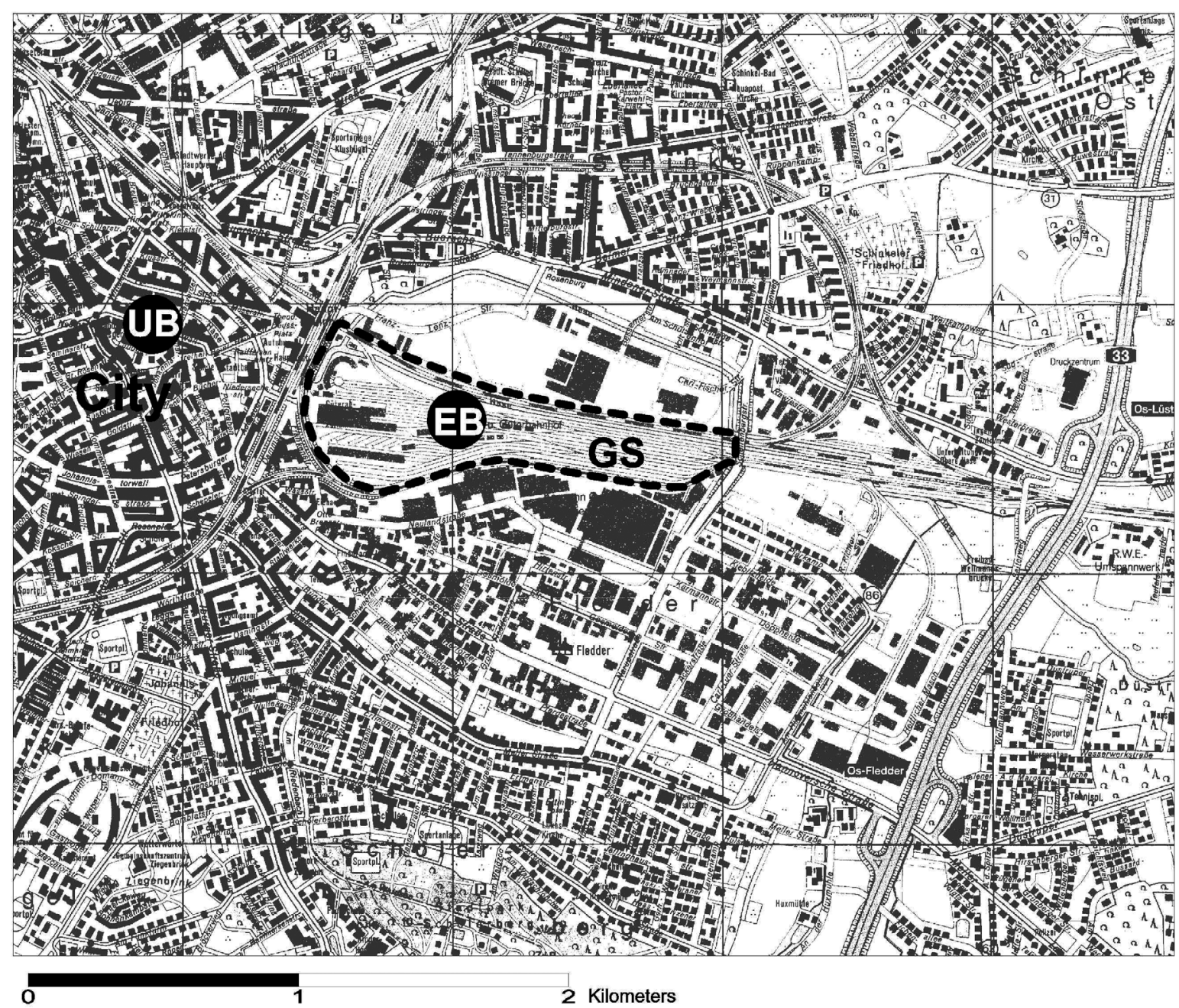

Fig. 1. The study area in Osnabrück, Germany. The area of the goods station (GS) is shown by a dashed line; the location of the energy balance station (EB) und urban centre station (UB, in 2001) are also shown 
with an average layer thickness of around 0.3 to $1 \mathrm{~m}$. At the measurement site the thickness of the ballast bulk is $0.5 \mathrm{~m}$. The dimensions of the individual ballast pieces vary from 2.5 to $7.1 \mathrm{~cm}$ in diameter and 1.35 to $3.5 \mathrm{~cm}$ in height, which was defined normal to the diameter. The porosity of the ballast bulk, defined by the ratio of the volume of air-filled cavities to the total bulk volume, is 0.45 .

The actual measurement point offered uniform fetch conditions of $>800 \mathrm{~m}$ to the east, $>175 \mathrm{~m}$ to the north and west and $100 \mathrm{~m}$ to the south. To assess whether the flux measurements represent the characteristics of the ballast surface, the analytical footprint model of Schuepp et al. (1990) was applied. It shows that under neutral stability ca. $90 \%$ of the cumulative flux is from a source area $\leq 175 \mathrm{~m}$ around the instrument location so that the properties of the ballast surface are portrayed by the flux measurements.

However, in terms of surface flux measurements, the site surroundings have to be considered heterogeneous with a mix of ballast, gravel, railway tracks and sparse vegetation in the flux footprint as well as light and electricity masts in the field of flow (Fig. 2). The consequences and limitations of the complex site properties on the flux estimates will be discussed in Section 5.

3.2. Instrumentation. The energy balance station (Stn EB) at the study site was equipped with a 3dimensional ultrasonic anemometer (USA-1, Metek) at $2.1 \mathrm{~m}$ above ground level (a.g.l.) which measured horizontal, lateral and vertical wind speeds at a $10 \mathrm{~Hz}$ sampling rate. The $10 \mathrm{~Hz}$ raw data were stored on a standard personal computer.

Dry- and wet-bulb temperatures were measured at 0.45 and $2.05 \mathrm{~m}$ a.g.l. by psychrometers equipped with

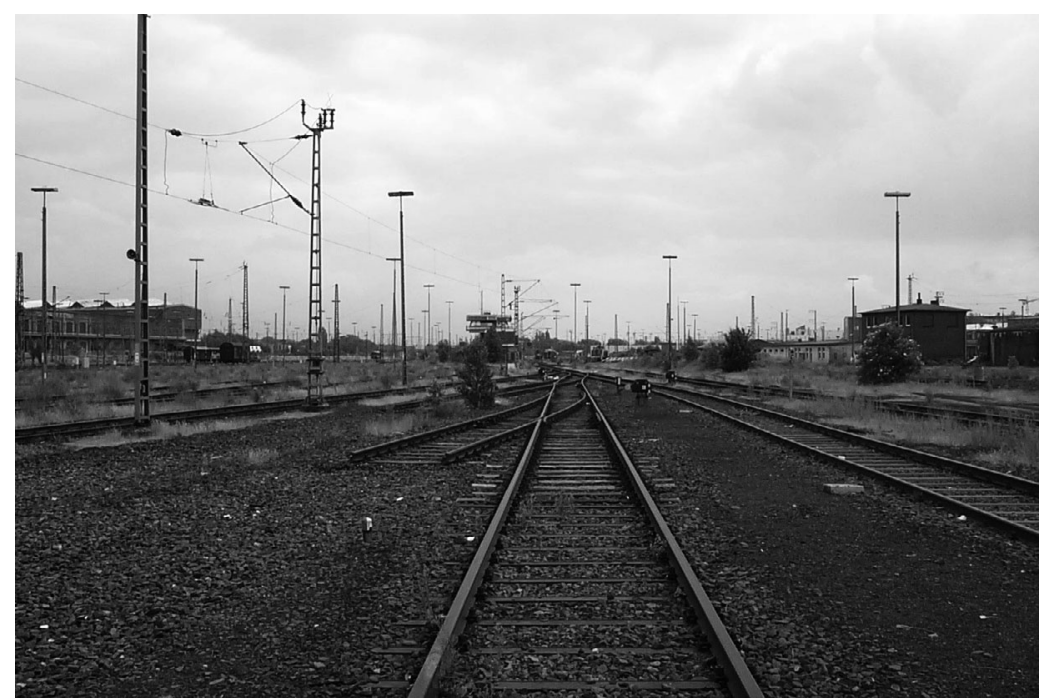

Fig. 2. Overview of the measurement site (view to the east) glass-coated PT 100s (Thies Clima). The dry-bulb temperatures are referred to as $T_{0.45 \mathrm{~m}}$ and $T_{2.05 \mathrm{~m}}$ hereafter. Net radiation $Q^{*}$ was measured by a Schulze type pyrradiometer (Thies Clima) at $2 \mathrm{~m}$ a.g.l. Soil temperatures were measured by thermistors (Thies Clima) placed within the ballast bulk at $-0.05 \mathrm{~m}\left(T_{\mathrm{b}}-0.05 \mathrm{~m}\right)$, $-0.1 \mathrm{~m}\left(T_{\mathrm{b}}-0.1 \mathrm{~m}\right)$ and $-0.3 \mathrm{~m}\left(T_{\mathrm{b}}-0.3 \mathrm{~m}\right)$. Additionally, a heat flux plate (HFP 01, Hukseflux) was installed at $-0.05 \mathrm{~m}$.

All data, except the sonic data, were sampled at $1 \mathrm{~Hz}$ and stored as 3 min averages (Data logger Combilog 1020, Th. Friedrichs).

3.3. Data handling. From sonic data and dry- and wet-bulb temperatures half hourly fluxes of $Q_{\mathrm{H}}$ and $Q_{\mathrm{E}}$ were calculated with the aid of software developed by the Department of Micrometeorology, University of Bayreuth, Germany (Foken 1999). Based on post-field Quality Assurance/Quality Control (QA/QC) tests implemented in the software (Foken \& Wichura 1996) more than $50 \%$ of the data (ca. $70 \%$ during clear and calm days) showed reasonable to good data quality during turbulent conditions in spite of the heterogeneity of the study site. Since the sonic anemometer was mounted vertically to the surface no coordinate rotation was applied. However, tests with rotated data (double rotation, cf. Aubinet et al. 2000) revealed that the effect of rotation on heat fluxes was negligible $\left(<4 \%, \mathrm{R}^{2}=0.99\right)$. Measurements over tall roughness elements indicated that it might be important to account for the time rate of change of storage of $Q_{\mathrm{H}}$ and $Q_{\mathrm{E}}$ in the air layer between the surface and the height of the sonic measurements since these terms can amount to $25 \mathrm{~W} \mathrm{~m}^{-2}$ (e.g. Vogt 1995). Storage terms were calculated (Thom 1975) but were negligible at this site, although for the sake of completeness the storage term for sensible heat $\left(Q_{\mathrm{SH}}\right)$ will be taken into account in Section 4.3.

Considering the complexity and heterogeneity of the ballast bulk (large air-filled cavities, varying grain size, heterogeneous geometry of individual ballast pieces) estimating $Q_{\mathrm{G}}$ precisely was not an easy task. However, based on a comparative analysis of different methods (Weber 2004, 2005) the $Q_{\mathrm{G}}$ presented in this paper were calculated according to Eq. (6) taking a laboratory-derived thermal conductivity of $\lambda=0.45 \mathrm{~W} \mathrm{~m}^{-1} \mathrm{~K}^{-1}$ into account. $\lambda$ was estimated in a laboratory set-up by measuring temperature gradients in the ballast and a reference substrate simultaneously under steady-state conditions (Weber 2004). The soil tem- 


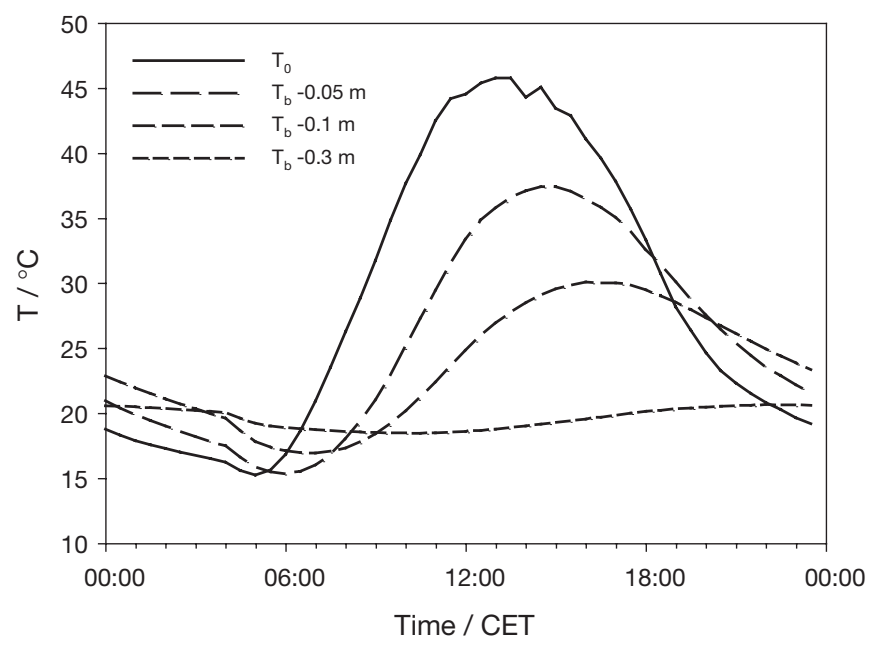

Fig. 3. Average diurnal courses of surface and ground temperatures of the ballast at the goods station in Osnabrück for 21 clear and calm days during the study period. Soil temperatures were measured by thermistors (Thies Clima) placed within the ballast bulk at $-0.05 \mathrm{~m}\left(T_{\mathrm{b}-0.05 \mathrm{~m}}\right),-0.1 \mathrm{~m}\left(T_{\mathrm{b}-0.1 \mathrm{~m}}\right)$ and $-0.3 \mathrm{~m}\left(T_{\mathrm{b}}-0.3 \mathrm{~m}\right)$

perature gradient in Eq. (6) was estimated from a modelled surface temperature $T_{0}$ (cf. Sozzi et al. 1999) and the in situ ground temperature measurement at $-0.05 \mathrm{~m}$.

In this study, all non-radiative fluxes directed away from the surface, to the atmosphere and into the ground, are assigned a positive sign.

The results presented here are based, if not specified otherwise, on 21 clear and calm days during the study period in 2002 during which urban climate effects were most pronounced. Those nights were defined according to stability and dispersion categories (Pasquill 1961, Polster 1969) from half hourly wind speed and net radiation input data. For long-term measurements, this approach is more straightforward in comparison to the boundary layer stability parameter $\zeta=z / L$ which can be gathered from the sonic measurements. However, it could be shown that both methods result in comparable stability definitions (Weber 2004). The criteria for the definition of clear and calm nights are given elsewhere (Weber \& Kuttler 2004).

\section{RESULTS}

\subsection{Thermal behaviour of the ballast facet}

In comparison to other urban surface and building materials the ballast bulk is characterised by relatively small values of thermal conductivity $\left(\lambda=0.45 \mathrm{~W} \mathrm{~m}^{-1}\right.$ $\left.\mathrm{K}^{-1}\right)$ and volumetric heat capacity $\left(C_{\mathrm{v}}=1.39 \times 10^{6} \mathrm{~J} \mathrm{~m}^{-3}\right.$ $\mathrm{K}^{-1}$ ). Due to its thermal properties this results in distinct daily amplitudes of surface and near-surface ground temperatures. Even on a somewhat damped average diurnal course for 21 clear and calm days during the study period the average daily temperature amplitude is $31 \mathrm{~K}$ at the surface and $22 \mathrm{~K}$ at $-0.05 \mathrm{~m}$ (Fig. 3). During noon hours the surface temperature can easily reach $46^{\circ} \mathrm{C}$ at the surface and $37^{\circ} \mathrm{C}$ at $-0.05 \mathrm{~m}$, since heat is not rapidly conducted down to deeper layers (small $\lambda$ ). Therefore, large near-surface to air temperature differences can develop during the day (Fig. 4). The temperature difference expressed

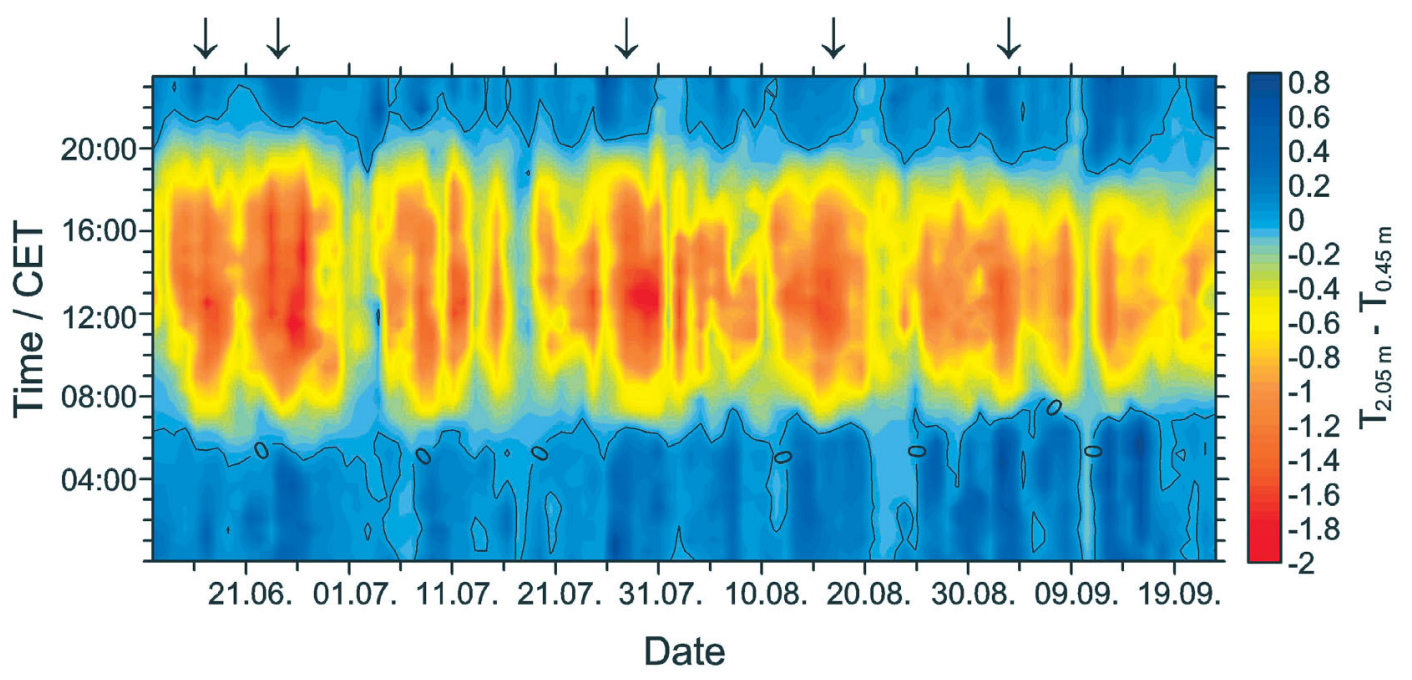

Fig. 4. Vertical temperature difference $\left(T_{2.05 \mathrm{~m}}-T_{0.45 \mathrm{~m}}\right)$ between the dry-bulb temperature measurements at $0.45 \mathrm{~m}$ above ground level (a.g.l.) $\left(T_{0.45 \mathrm{~m}}\right)$ and $2.05 \mathrm{~m}$ a.g.l. $\left(T_{2.05 \mathrm{~m}}\right)$ for the entire study period from June 12 to September 23, 2002, based on 30 min averages. Arrows indicate contiguous periods of $>1$ clear and calm days (17 to 20 June, 2002; 26 to 27 June, $2002 ; 27$ to 29 July, 2002; 15 to 20 August, 2002; and 2 to 3 September, 2002) 
here as the difference between $T_{2.05 \mathrm{~m}}$ and the near-surface measurement $T_{0.45 \mathrm{~m}}$ reaches -1.5 to $-2 \mathrm{~K}$ during noon hours, which is an equivalent lapse rate of -7.3

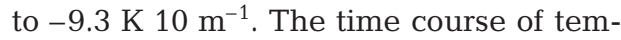
perature differences clearly shows periods of contiguous clear and calm days which are characterised by midday temperature differences of $-2 \mathrm{~K}$ (arrows in Fig. 4). Surface materials with small volumetric heat capacities are able to cool rapidly during the evening and nocturnal periods (Asaeda et al. 1996). Heat can be released relatively fast during the evening hours, especially when it is stored within a shallow layer near the surface during the daytime, as is the case for the ballast in Osnabrück (damping depth of the ballast $z_{\mathrm{d}}=-0.09 \mathrm{~m}$ ) it. $T_{0}$ starts to decrease in the early afternoon and drops below the ground temperatures $T_{\mathrm{b}-0.05 \mathrm{~m}}$ and $T_{\mathrm{b}-0.1 \mathrm{~m}}$ in the course of the evening (Fig. 3). With the highest
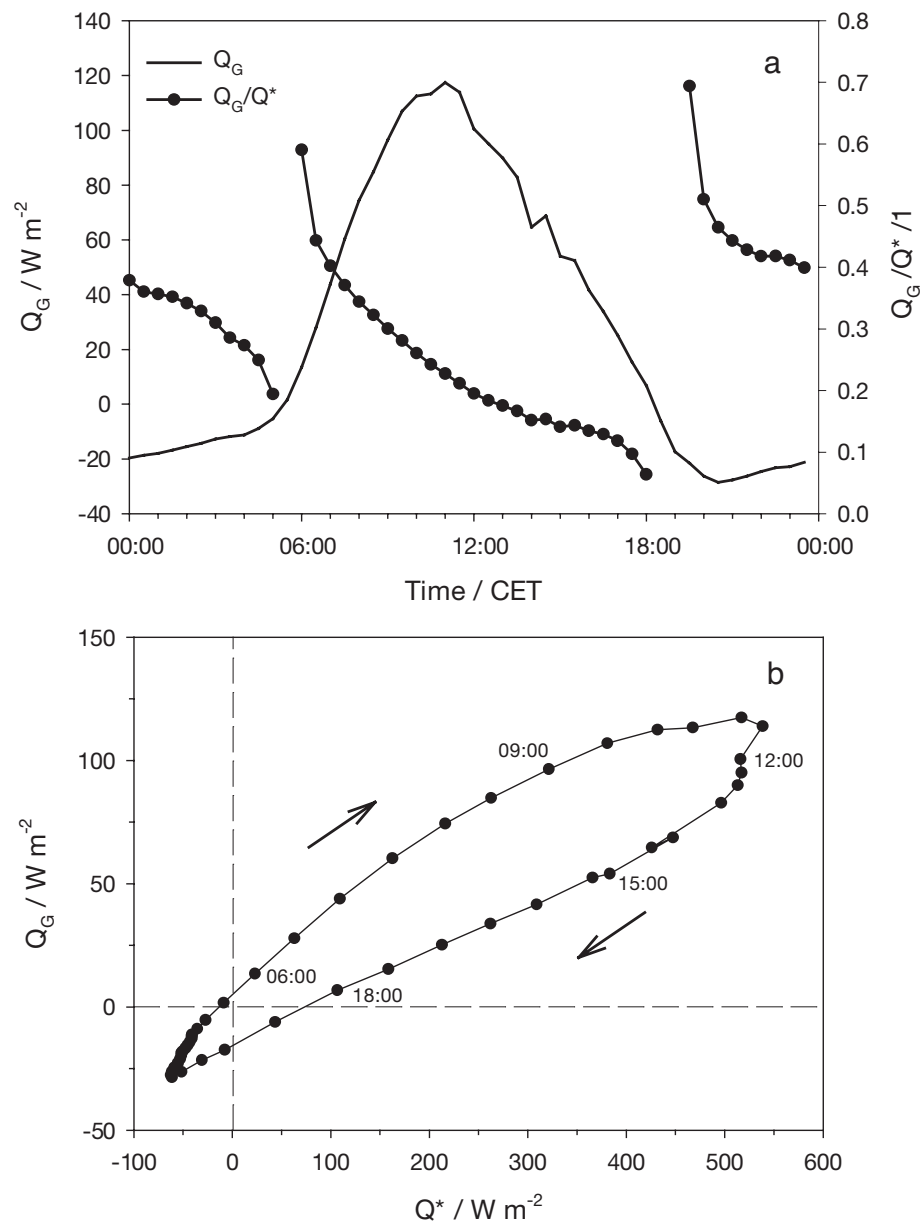

Fig. 5. (a) Diurnal course of the ground heat flux $Q_{\mathrm{G}}$ and the dimensionless flux ratio $Q_{\mathrm{G}} / Q^{*}$ and (b) a scatter plot of $Q^{*}$ versus $Q_{\mathrm{G}}$. Both plots are based on average diurnal courses for 21 clear and calm days in the study period temperature values of $T_{\mathrm{b}-0.3 \mathrm{~m}}$ in the early morning the entire ballast bulk has cooled down. A similar behaviour is visible in the near surface air temperature distribution. From around 20:30 h CET $T_{0.45 \mathrm{~m}}$ drops below $T_{2.05 \mathrm{~m}}$ so that a surface inversion develops which reaches an inversion strength of up to $T_{2.05 \mathrm{~m}}-T_{0.45 \mathrm{~m}}=$

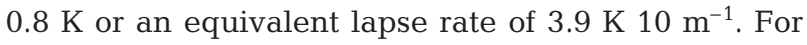
Stn EB in Osnabrück cooling rates of the ballast surface during 21 clear and calm nights are on average 1.1 $\mathrm{K} \mathrm{h}^{-1}$. The thermal behaviour of the ballast as described above is also evident in thermal imagery of urban areas. Ballast surfaces at stations and goods stations belong to the warmest urban surface types during the day but to the coldest during morning hours (Weber 2004).

\subsection{Ground heat fluxes}

The time course of $Q_{\mathrm{G}}$ is governed by the temperature distribution within the ballast bulk. The surface temperature promptly reacts to absorption of short wave radiation after sunrise, but the temperature wave requires roughly $90 \mathrm{~min}$ to penetrate to a depth of $-0.05 \mathrm{~m}$ (result of cross-correlation between $T_{0}$ and $T_{\mathrm{b}-0.05 \mathrm{~m}}$ temperature data, not shown here). Due to an increasing temperature gradient $Q_{\mathrm{G}}$ sharply increases shortly after sunrise and peaks during noon, with maximum values of about $120 \mathrm{~W} \mathrm{~m}^{-2}$ (Fig. 5a). With the start of insolation $60 \%$ of the incoming energy $\left(=Q^{*}\right)$ is converted into $Q_{\mathrm{G}}\left(Q_{\mathrm{G}} / Q^{*}=\right.$ $0.6)$, although the flux ratio constantly decreases to a value of $Q_{\mathrm{G}} / Q^{*}=0.2$ at 12:00 h CET (Fig. 5a). With smaller temperature gradients between $T_{0}$ and $T_{\mathrm{b}}$ $-0.05 \mathrm{~m}$ the absolute values of $Q_{\mathrm{G}}$ also decrease during the afternoon. At around 18:30 to 19:00 h CET $Q_{\mathrm{G}}$ changes sign and shows relatively small absolute values of around -20 to $-15 \mathrm{~W} \mathrm{~m}^{-2}$ during night-time. The relative importance of $Q_{\mathrm{G}}$ in converting $Q^{*}$ is pronounced during the morning and evening hours (Fig. 5a) with flux ratios $Q_{\mathrm{G}} / Q^{*}$ in the same order of magnitude. However, when comparing absolute values more energy is converted into $Q_{\mathrm{G}}$ during the 
morning period. This behaviour is expressed in a clockwise hysteresis-loop when plotting the time series $Q^{*}$ versus $Q_{\mathrm{G}}$ (Fig. $5 \mathrm{~b}$ ). Asaeda et al. (1996) note that this is a common feature of substrates and surface types converting the dominant fraction of available energy to $Q_{\mathrm{G}}$ during the morning period. In daylight hours $\left(Q^{*}>0\right)$ around $20 \%$ of $Q^{*}$ is converted into $Q_{\mathrm{G}}($ Table 1).

\subsection{Turbulent heat fluxes}

A composite of the measured energy fluxes during 21 clear and calm days shows that $Q_{\mathrm{H}}$ is the dominant part of the energy budget (Fig. 6). $Q_{\mathrm{H}}$, which is driven by the large surface to air temperature gradient (cf. Fig. 4), reaches values of around $200 \mathrm{~W} \mathrm{~m}^{-2}$ at around noon $(13: 30 \mathrm{~h}$ CET), resulting in a flux ratio of $Q_{\mathrm{H}} / Q^{*}=0.39$ (Fig. 7). The ratio $Q_{\mathrm{H}} / Q^{*}$ continuously increases in magnitude during the course of the day to a value of 0.79 before sunset.

Due to the sparse vegetation at the site $Q_{\mathrm{E}}$ is of minor importance in the energy budget, with maximum values of $79 \mathrm{~W} \mathrm{~m}^{-2}$ during the afternoon (15:00 h CET, Fig. 6). This is a general behaviour of $Q_{\mathrm{E}}$ at this site which is also valid for the entire study period. Even after precipitation events water is able to drain relatively fast through the porous ballast bulk so that $Q_{\mathrm{E}}$ is not significantly larger during those periods. Bowen ratios (Bo) are large during the day, with average maximum values of $\mathrm{Bo}=4$ on a $30 \mathrm{~min}$

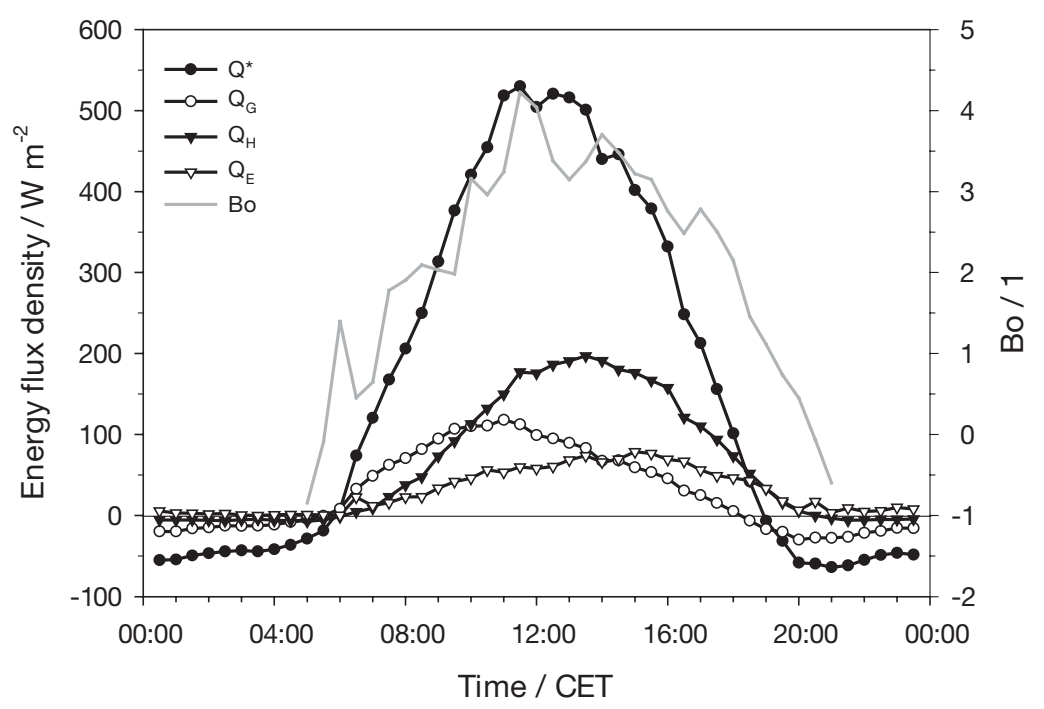

Fig. 6. Energy balance composite for 21 clear and calm days during the study period from 12 June to 23 September, 2002, at the goods station in Osnabrück based on 30 min averages. Bo: Bowen ratio basis. However, Bo values can be as large as Bo $=10$ to 11 . Note that due to large scatter because of small vertical humidity gradients nocturnal Bo are not plotted in Fig. 6.

After $Q^{*}$ becomes negative in the evening $\left(Q^{*}<0\right)$ $Q_{\mathrm{H}}$ is still positive and directed towards the atmosphere. This is quite common and comparable to other urban surfaces. However, with a time-shift of around $1.5 \mathrm{~h}$ after $Q^{*}$ changes sign, $Q_{\mathrm{H}}$ decreases to values $<0$. Sensible heat is now transported to the ground, resulting in consecutive cooling of the near-surface atmosphere. This is also indicated by a positive flux ratio $Q_{\mathrm{H}} / Q^{*}$ from around 21:00 h CET onwards (Fig. 7). This behaviour is in contrast to other urban surfaces, which are reported to maintain positive $Q_{\mathrm{H}}$ through the course of the night due to the high surface temperatures of urban areas (Oke 1997, Anandakumar 1999).

Average flux ratios for the 21 clear and calm days are given in Table 1. Although the turbulent heat fluxes $Q_{\mathrm{H}}$ and $Q_{\mathrm{E}}$ account for the conversion of $52 \%$ of the incoming energy, the influence of $Q_{\mathrm{E}}$ is small. During the day, $Q_{\mathrm{H}}$ is more than twice as large as $Q_{\mathrm{E}}$ and is the dominant part of the energy budget followed by $Q_{\mathrm{G}}$, accounting for $20 \%$. The influence of storage of sensible heat $Q_{\mathrm{SH}}$ below the measurement height of the sonic anemometer is negligible during both the day and night. 


\subsection{Energy balance closure}

During recent years an increasing number of studies had to conclude that the surface energy balance equation cannot be fully closed, leaving a residual term of around 1 to $45 \%$ or 100 to $250 \mathrm{~W} \mathrm{~m}^{-2}$ in absolute numbers (Panin et al. 1998, Wilson et al. 2002). This means that the energy balance components for some reason do not account for all the incoming energy (for detailed discussions on that topic see Foken \& Oncley 1995 or Wilson et al. 2002). The magnitude of the residual in the surface energy balance equation at our site is Res $/ Q^{*}=0.28$ during the day $\left(\operatorname{Res} / Q^{*}=0.61\right.$ during the night, but absolute values are small). The overall energy balance closure for the entire study period at Stn EB in Osnabrück as evaluated from the energy balance ratio (EBR, cf. Wilson et al. 2002) is $70 \%$ :

$$
\operatorname{EBR}=\frac{\sum\left(Q_{\mathrm{E}}+Q_{\mathrm{H}}\right)}{\sum\left(Q^{*}-Q_{\mathrm{G}}\right)}
$$

Reasons for the non-closure of the surface energy balance equation at this site will be briefly discussed in the next section.

\section{DISCUSSION}

\subsection{Surface energy balance}

Due to the methodological constraints of urban flux measurements in general regarding limited fetch, complex vertical structure of the urban atmosphere and heterogeneity of the measurement site, energy balance studies of specific urban facets are rare. Apart from the urban facet energy balance studies of Asaeda et al. (1996) and Anandakumar (1999) dealing with pavement and asphalt, respectively, our results can only roughly be compared to local-scale urban energy balance studies. However, it is evident that $Q_{\mathrm{H}}$ is the

Table 2. Average flux ratios from different urban sites. Averaging interval is daytime $Q^{*}>0$ for all sites

$\left.\begin{array}{lcccll}\hline \text { Site } & Q_{\mathrm{H}} / Q^{*} & Q_{\mathrm{E}} / Q^{*} & Q_{\mathrm{G}}{ }^{\mathrm{a}} / Q^{*} & \text { Bo } & \text { Source } \\ \hline \text { Mexico City } & 0.38 & 0.04 & 0.58 & 8.8 & \text { Oke et al. (1999) } \\ \text { Basel } & 0.48 & 0.18 & 0.38 & 2.62 & \text { Christen \& Vogt (2004) } \\ \text { Barcelona } & 0.34 & 0.09 & 0.56 & 7.1 & \text { Jauregui et al. (2002) } \\ \text { Tucson } & 0.47 & 0.25 & 0.28 & 1.83 & \text { Grimmond \& Oke (1995) } \\ \text { Los Angeles } & 0.35 & 0.25 & 0.40 & 1.4\end{array}\right\}$

${ }^{a}$ In the urban context this term is normally referred to as heat storage $\Delta \mathrm{QS}$. This term accounts not only for heat flux into the ground but incorporates heat storage in the air volume between the measurement height and the surface dominant term at all urban sites, ranging from $0.35<$ $Q_{\mathrm{H}} / Q^{*}<0.48$, while $Q_{\mathrm{E}}$ is generally of minor importance in a range of $0.04<Q_{\mathrm{E}} / Q^{*}<0.25$ (Table 2). Urban $Q_{\mathrm{E}}$ estimates have been shown to be very sensitive to the fraction of green within the flux footprint as well as to irrigation processes (Grimmond \& Oke 1995, Christen \& Vogt 2004). The comparison of $Q_{\mathrm{G}}$ to other studies is difficult since it is mostly calculated as the residual of the surface energy balance equation with the problem of accumulating measurement errors in that term. Local-scale urban $Q_{\mathrm{G}}$ estimates range from $0.28<Q_{\mathrm{G}} / Q^{*}<0.58$ (Table 2 ) and they are comparable to the magnitudes of asphalt and pavement sites given with $Q_{\mathrm{G}} / Q^{*} \approx 0.5$ (Asaeda et al. 1996, Anandakumar 1999). With a value of $Q_{\mathrm{G}} / Q^{*}=0.2$ the ballast bulk seems to be a smaller sink for heat on average, although comparison is difficult due to residual calculation as mentioned above.

Based on the results presented the ballast energy balance characteristics are similar to other urban sites and facets during the day (cf. Table 1), but during the night this behaviour changes. Most urban surfaces release the heat that was stored in the building mass during the daytime into the atmosphere. As a result, upward directed $Q_{\mathrm{H}}$ can be observed overnight (urban heat island effect). In contrast, the ballast surface can cool significantly during the course of the night due to its thermal properties (cf. Section 4.1). From around 21:00 $\mathrm{h}$ CET the ballast is characterised by negative values of $Q_{\mathrm{H}}$ and subsequent cooling of the near-surface air layer. In terms of its thermal behaviour the ballast can be considered a typical urban surface type during the day but as an untypical one ('rural-like') during the night.

The effect of the ballast energy balance on the urban climate can to some extent be demonstrated by nearsurface air temperature measurements which were performed at $2 \mathrm{~m}$ a.g.l. at Stn EB and in the urban centre of Osnabrück (UB, Fig. 1) in the summer of 2001 (for details see Weber \& Kuttler 2004). During clear and calm nights near-surface air masses with average velocities of around $1 \mathrm{~m} \mathrm{~s}^{-1}$ were typically directed westwards into the direction of UB as was demonstrated by tracer dispersion experiments (Weber \& Kuttler 2004) and a numerical cold-air model (Weber 2004). Due to cooling of the near-surface air layers above the ballast facet, a horizontal air temperature difference of on average $0.8 \mathrm{~K}$ (maximum $=3 \mathrm{~K}$ ) at $2 \mathrm{~m}$ a.g.l. existed between UB and Stn EB. Despite the relatively small area of the ballast facet (cf. Section 3.1) a somewhat positive 
effect of the ballast facet on the urban climate of Osnabrück by cooling near-surface air masses is evident.

\subsection{Energy balance closure}

In spite of the complexity of the urban flux methodology, measurements were conducted at the GS in Osnabrück. Due to the absence of large roughness elements and sufficient fetch to all wind directions near the surface, energy balance measurements at $2 \mathrm{~m}$ a.g.l. were achieved with a good degree of accuracy (cf. Section 3.3).

However, a surface energy balance non-closure of $30 \%$ was reported (Section 4.4). This is in the same order of magnitude as is visible in other studies. Even campaigns conducted over homogeneous and flat terrain using a variety of state-of-the-art equipment reported closure gaps of 20 to $35 \%$ (Foken 2003). In consideration of enhanced measurement accuracy, reasons for the non-closure of the energy balance are increasingly attributed to methodological uncertainties. We believe a mixture of reasons might be true for the explanation of the closure gap at our site. Since the residual of the surface energy balance equation shows a marked diurnal course a sort of systematic underestimation of energy conversion into one of the 3 fluxes seems likely. However, all terms were checked to have been measured accurately and no source of error became evident. During the night, cold air flows were observed in the GS area (Weber \& Kuttler 2004), which may account for non-stationary data during the measurement intervals. However, nocturnal fluxes are of small absolute value so that resulting flux errors are small. Finally, similar sources for the closure gap, as previously discussed by other authors, seem to be likely for the present measurements: heterogeneity of the site, different footprints of the fluxes, measurement errors and possible non-turbulent horizontal advection (e.g. Foken \& Wichura 1996, Grünhage et al. 2000, Massman \& Lee 2002). Testing for all of these reasons would have resulted in far more methodological demands and were beyond the scope of the somewhat more applied approach of this research.

\section{CONCLUDING REMARKS}

During a 3 month study period, turbulent and ground heat fluxes were measured at an inner urban ballast facet. The surface can be characterised as typically urban with high surface temperatures during the day and the dominant part of incoming energy converted into heating the near-surface atmosphere. The flux estimates are comparable to other urban facets as well as to urban flux estimates on a local scale. During night, however, the thermal behaviour is untypical for an urban surface. With negative sensible heat fluxes and significant near-surface cooling the ballast is among the coolest urban surfaces at sunrise. In terms of nocturnal thermal behaviour the ballast is referred to as a 'rural-like' surface type.

Flux measurements at complex sites may involve difficulties in methodology and interpretation but the present study has shown that they can also produce good quality data which helps to better understand microclimatic variations of different surface types. Finally, our findings support the statement of Arnfield (2003) that it is important to know more about the energy budget of specific and different urban facets in order to enhance the understanding of urban climatic phenomena in general.

Acknowledgements. The possibility to use the flux calculation software 'Bayreuther Turbulenzknecht' (developed by Prof. Th. Foken, Department of Micrometeorology, University of Bayreuth, Germany) in this study is greatly appreciated.

\section{LITERATURE CITED}

Anandakumar K (1999) A study on the partition of net radiation into heat fluxes on a dry asphalt surface. Atmos Environ 33:3911-3918

Arnfield J (2001a) Micro- and mesoclimatology. Prog Phys Geog 25:123-133

Arnfield J (2001b) Micro- and mesoclimatology. Prog Phys Geog 25:560-569

Arnfield J (2003) Two decades of urban climate research: a review of turbulence, exchanges of energy and water, and the urban heat island. Int J Climatol 23:1-26

Arya PS (2001) Introduction to micrometeorology. Academic Press, San Diego, CA

Asaeda T, Vu CT (1997) Effects of different pavements on the urban thermal environment. 12th Conference on Boundary Layers and Turbulence. American Meteorological Society, Boston, MA, p 470-471

Asaeda T, Ca VT, Wake A (1996) Heat storage of pavement and its effect on the lower atmosphere. Atmos Environ 30: 413-427

Aubinet M, Grelle A, Ibrom A, Rannik U and 16 others (2000) Estimates of the annual net carbon and water exchange of forests: the EUROFLUX methodology. Adv Ecol Res 30: 113-175

Barlow J, Harman I, Belcher S (2004) Scalar fluxes from urban street canyons. Part I: Laboratory simulation. BoundaryLayer Meteorol 113:369-385

Barradas VL, Tejeda-Martinez A, Jauregui E (1999) Energybalance measurements in a suburban vegetated area in Mexico City. Atmos Environ 33:4109-4113

Businger JA, Wyngaard JC, Izumi T, Bradley E (1971) Fluxprofile relationships in the atmospheric surface layer. J Atmos Sci 28:181-189

Christen A, Vogt R (2004) Energy and radiation balance of a central European city. Int J Climatol 24:1395-1421

Christen A, Bernhofer C, Parlow E, Rotach M, Vogt R (2003) 
Partitioning of turbulent fluxes over different urban surfaces. Proc 5th Int Conf Urban Clim (ICUC-5), September 1-5, 2003, Lodz, Poland. Dept of Meteorology and Climatology, Faculty of Geographical Sciences, Univ of Lodz

Dabberdt WA, Lenschow DH, Horst TW, Zimmermann PR, Oncley S, Delany AC (1993) Atmosphere-surface exchange measurements. Science 260:1472-1481

Foken T (2003) Angewandte Meteorologie-mikrometeorologische Methoden. Springer, Heidelberg

Foken T, Oncley S (1995) Results of the workshop 'Instrumental and methodical problems of land surface flux measurements'. Bull Am Meterol Soc 76:1191-1193

Foken T, Wichura B (1996) Tools for quality assessment of surface-based flux measurements. Agric For Meteorol 78: 83-105

Grimmond CSB, Oke TR (1995) Comparison of heat fluxes from summertime observations in the suburbs of four North American cities. J Appl Meteorol 34:873-889

Grimmond CSB, Oke TR (2002) Turbulent heat fluxes in urban areas: observations and a local-scale urban meteorological parameterisation scheme (LUMPS). J Appl Meteorol 41:792-810

Grimmond CSB, Salmond J, Offerle B, Oke TR (2002) Localscale surface flux measurements at a downtown site in Marseille during the ESCOMPTE field campaign. Fourth Symposium on the Urban Environment, May 20-24, 2002, Norfolk. American Meteorological Society, Boston, MA

Grünhage L, Haenel HD, Jäger HJ (2000) The exchange of ozone between vegetation and atmosphere: micrometeorological measurement techniques and models. Environ Pollut 109:373-392

Harman I, Barlow J, Belcher S (2004) Scalar fluxes from urban street canyons. Part II: Model. Boundary-Layer Meteorol 113:387-410

Jauregui E, Moreno MC, Tejeda A (2002) The energy-balance of central Barcelona. Fourth Symposium on the Urban Environment, May 20-24, 2002, Norfolk. American Meteorological Society, Boston, MA

Liu H, Foken T (2001) A modified Bowen-ratio method to determine sensible and latent heat fluxes. Meteorol Z 10: $71-80$

Liu H, Peters G, Foken T (2001) New equations for sonic temperature variance and buoyancy heat flux with an omnidirectional sonic anemometer. Boundary-Layer Meteorol 100:459-468

Marth L (2000) Surface heterogeneity and vertical structure of the boundary layer. Boundary-Layer Meteorol 96:33-62

Massman WJ, Lee X (2002) Eddy covariance flux corrections and uncertainties in long-term studies of carbon and energy exchanges. Agric For Meteorol 113:121-144

McKendry IG (2003) Applied climatology. Prog Phys Geog 27 : 597-606

Nieuwstadt FTM (1984) The turbulent structure of the stable nocturnal boundary layer. J Atmos Sci 41:2202-2216

Nunez M, Oke TR (1977) The energy-balance of an urban canyon. J Appl Meteorol 16:11-19

Oke TR (1987) Boundary layer climates. Methuen, London

Oke TR (1997) Urban environments. In: Bailey WG, Oke TR, Rouse WR (eds) The surface climates of Canada. McGillQueen's University Press, Montreal, p 303-327

Oke TR, Spronken-Smith RA, Jauregui E, Grimmond CSB (1999) The energy-balance of central Mexico City during

Editorial responsibility: Helmut Mayer,

Freiburg, Germany the dry season. Atmos Environ 33:3919-3930

Panin GN, Tetzlaff G, Raabe A (1998) Inhomogeneity of the land surface and problems in the parameterisation of surface fluxes in natural conditions. Theor Appl Climatol 60: 163-178

Panofsky HA, Tennekes H, Lenschow DH, Wyngaard JC (1977) The characteristics of turbulent velocity components in the surface layer under convective conditions. Boundary-Layer Meteorol 11:355-361

Pasquill F (1961) The estimation of the dispersion of windborne material. Meteorol Mag 90(1):33-49

Polster G (1969) Erfahrungen mit Strahlungs-, Temperaturgradient-, und Windmessungen als Bestimmungsgrößen der Diffusionskategorien. Meteorol Rundschau 22: 170-175

Roberts SM, Oke TR, Voogt JA, Grimmond CSB, Lemonsu A (2003) Energy storage in a european city center. Fifth International Conference on Urban Climate, September 1-5, 2003, Lodz, Poland

Rotach MW (1999) On the influence of the urban roughness sublayer on turbulence and dispersion. Atmos Environ 33: 4001-4006

Roth M (2000) Review of atmospheric turbulence over cities. Q J R Meteorol Soc 126:941-990

Schmid HP, Lloyd CR (1999) Spatial representativeness and the location bias of flux footprints over inhomogeneous areas. Agric For Meteorol 93:195-209

Schuepp PH, Leclerc MY, MacPherson JI, Desjardins RL (1990) Footprint prediction of scalar fluxes from analytical solutions of the diffusion equation. Boundary-Layer Meteorol 50:355-373

Sozzi R, Salcido A, Flores RS, Georgiadis T (1999) Daytime net radiation parameterisation for Mexico City suburban areas. Atmos Res 50:53-68

Spronken-Smith R, Oke TR, Lowry WP (2000) Advection and the surface energy-balance across an irrigated urban park. Int J Climatol 20:1033-1047

Thom AS (1975) Momentum, mass and heat exchange of plant communities. In: Monteith JL (ed) Vegetation and the atmosphere: principles, Vol 1. Academic Press, London, p 57-109

Vogt R (1995) Theorie, Technik und Analyse der experimentellen Flussbestimmung am Beispiel des Hartheimer Kiefernwaldes. Stratus Band 3, Geographisches Institut, Universität Basel

Weber S (2004) Energiebilanz und Kaltluftdynamik einer urbanen Luftleitbahn (=Energy balance and cold-air dynamics of an urban ventilation path), Band 21. Essener Ökologische Schriften, Westarp Wissenschaften, Hohenwarsleben

Weber S (2005) Comparison of in-situ measured ground heat fluxes within a heterogeneous urban ballast layer. Theor Appl Climatol (in press)

Weber S, Kuttler W (2004) Cold-air ventilation and the nocturnal boundary layer structure above an urban ballast facet. Meteorol Z 13:405-412

Wilson $\mathrm{K}$, Goldstein A, Falge E, Aubinet M and 16 others (2002) Energy-balance closure at FLUXNET sites. Agric For Meteorol 113:223-243

Wyngaard JC (1990) Scalar fluxes in the planetary boundary layer-theory, modelling, and measurement. BoundaryLayer Meteorol 50:49-75

Submitted: December 13, 2004; Accepted: February 16, 2005 Proofs received from author(s): March 7, 2005 